\title{
The challenge of diagnosing tuberculosis in children
}

\author{
O desafio de diagnosticar a infecção tuberculosa na criança \\ El desafío de diagnosticar la infección tuberculosa en el niño
}

Regina Célia de M. Succi ${ }^{1}$

While we have made some progress towards the Millennium Development Goals ${ }^{(1)}$, which were agreed in 2010 by the World Health Organization - "to reduce by half the incidence and mortality of Tuberculosis by 2015 , compared to values of $1990 "-$, Brazil still ranks 17 th among countries with the highest TB burden in the world ${ }^{(2)}$. The early and effective treatment of all cases of tuberculosis is the primary measure to save around 1.5 million lives each year ${ }^{(2)}$. However, often, when diagnosis and treatment are being performed, many people (contacts) have already been infected, most of them children who, besides controlling less effectively the replication of the $M$. tuberculosis, progress more rapidly and frequently to pulmonary and extrapulmonary forms of the disease ${ }^{(3-5)}$.

The identification and treatment of latent tuberculosis infection reduce the risk of progression to the active disease, particularly in high-risk groups, such as children under 5 years old, infected with HIV and on immunosuppressive therapy ${ }^{(6,7)}$. However, an early and accurate diagnosis of TB infection in children is still a great challenge. In addition to the tuberculin skin test - TST (used for over 100 years), in the last decade researchers have developed tests using peripheral blood samples that measure the release of interferon-gamma (IFN- $\gamma$ ) from T host cells infected by $M$. tuberculosis ${ }^{(8)}$. These tests, called Interferon-Gamma Release Assays (IGRAs), present advantages in relation to the tuberculin test: the results may be obtained in one or two days, do not require return visits for reading the skin reaction and, if repeated, do not present a booster effect. The three antigens used for the IGRA tests (ESAT-6, CFP10 , and TB7.7) are not contained in BCG vaccine and in

Instituição: Escola Paulista de Medicina da Universidade Federal de São Paulo (Unifesp), São Paulo, SP, Brasil

'Departamento de Pediatria da Escola Paulista de Medicina da Unifesp, São Paulo, SP, Brasil most other mycobacteria, while tuberculin (PPD) contains more than 200 antigens, which reduces its specificity. Two commercial kits are available: QuantiFERON-TB Gold in Tube, which assesses the levels of IFN- $\gamma$ produced after antigen stimulation, and the T-Spot.TB test, which quantifies the mononuclear cells producing IFN- $\gamma$ after in vitro stimulation.

Over the past 3 years, three systematic reviews and metaanalyzes have been published ${ }^{(9-1)}$, concerning the IGRA tests in the pediatric population, revealing a very high specificity (95-100\%) - exceeding that of the Tuberculin Test (TST) -, and a lower sensitivity (80-90\%), depending on the age of the subjects and their condition of imunocompetence (8-11). This suggests that the TST and the IGRAs have similar accuracy in detecting infection or disease in children, but the interpretation of results is difficult due to the absence of a definitive marker of these conditions in children.

The study by Vallada et al $l^{(12)}$, published in this issue of the journal, assessed the accuracy of one Igra tests (QuantiFERON-TB Gold in Tube) in the diagnosis of tuberculosis in children and showed a positive predictive value of $81.8 \%$ (95\%CI $46.3-97.4$ ), sensitivity of $81.8 \%$ (95\% CI 48.2-97.2), and specificity of $98.8 \%$ (95\% CI 96-99.8). However, the small sample of children assessed with tuberculosis (latent or active disease) diminishes the power of the study in its definitive findings. A strong point of the research, however, is the low age of participants (seven of the 11 children were younger than 5 years and five presented a positive test). Only two children defined by the study criteria as infected presented a negative QuantiFERON-TB Gold in Tube test, both with active
Endereço para correspondência:

Regina Célia de M. Succi

Avenida Doutor Altino Arantes, 198, casa 03

CEP 04042-001 - São Paulo/SP

E-mail: succi@picture.com.br

Conflito de interesse: nada a declarar

Recebido em: 2/10/2013 
disease and under 3 years of age. Even considering that the 11 children have received BCG at birth, the test presented a good relationship with the TST, which was $\geq 10 \mathrm{~mm}$ in the nine children who performed it.

Important implications of the study are: the good relationship with the tuberculin skin test, even in young children, and the fact that, despite its high negative predictive value, a negative test cannot rule out the diagnosis of tuberculosis (infection or disease) in children. If we seek greater specificity in children who received the BCG vaccine, the IGRA tests are better than the TST, but if we want greater sensitivity, both tests can be performed. In immunocompromised

\section{References}

1. Stop TB Partnership; World Health Organization. The Global Plan to Stop TB 2011-2015: Transforming the fight towards elimination of tuberculosis. Geneva: WHO; 2011.

2. World Health Organization. Global tuberculosis report 2012. Geneva: WHO; 2012.

3. Marais BJ, Gie RP, Schaaf HS, Hesseling AC, Obihara CC, Starke JJ et al. The natural history of childhood intra-thoracic tuberculosis: a critical review of literature from the pre-chemotherapy era. Int J Tuberc Lung Dis 2004;8:392-402.

4. Dye C, Williams BG. The population dynamics and control of tuberculosis. Science 2010;328:856-61.

5. Ottenhoff TH, Kaufmann SH. Vaccines against tuberculosis: where are we and where do we need to go? PLoS Pathog 2012;8:e1002607.

6. Parekh M, Schluger N. Treatment of latent tuberculosis infection. Ther Adv Respir Dis 2013;7:351-6.

7. Sociedade Brasileira de Pneumologia e Tisiologia para o Manejo da Asma 2012. III Diretrizes para Tuberculose da Sociedade Brasileira de Pneumologia e Tisiologia. J Bras Pneumol 2009;35:1018-48. children, including those affected with HIV, the combination of both tests should be preferred.

The Interferon-Gamma Release Assays have not been validated as a routine diagnostic procedure for tuberculosis in Brazil. The possibility of excluding tuberculosis infection in children vaccinated with BCG, and the positive tuberculin reactions make the IGRAs important instruments to diagnose tuberculosis infection in our country. However, although more specific than the TST, these tests are not capable to differentiate latent tuberculosis infection from tuberculosis disease, which still requires clinical and radiological criteria for its definition.

8. Ferrara G, Losi M, D'Amico R, Roversi P, Piro R, Meacci M et al. Use in routine clinical practice of two commercial blood tests for diagnosis of infection with Mycobacterium tuberculosis: a prospective study. Lancet 2006;367:1328-34.

9. Mandalakas AM, Detjen AK, Hesseling AC, Benedetti A, Menzies D. Interferongamma release assays and childhood tuberculosis: systematic review and meta-analysis. Int J Tuberc Lung Dis 2011;15:1018-32.

10. Sun L, Xiao J, Miao Q, Feng WX, Wu XR, Yin QQ et al. Interferon gamma release assay in diagnosis of pediatric tuberculosis: a meta-analysis. FEMS Immunol Med Microbiol 2011;63:165-73.

11. Machingaidze S, Wiysonge CS, Gonzalez-Angulo Y, Hatherill M, Moyo S, Hanekom $W$ et al. The utility of an interferon gamma release assay for diagnosis of latent tuberculosis infection and disease in children: a systematic review and meta-analysis. Pediatr Infect Dis J 2011;30:694-700.

12. Vallada MG, Okay TS, Del Negro GM, Antonio CA, Yamamoto L, Ramos SR. Acurácia do QuantiFERON-TB Gold in Tube no diagnóstico de tuberculose em uma população pediátrica jovem previamente vacinada com BCG. Rev Paul Pediatr 2014;32:4-10. 